\title{
INFLUENCE OF PARAMETERIZATION OF SOIL PROCESSES ON METEOROLOGICAL FORECASTS OF VERTICAL PROFILES
}

\author{
WPLYW PARAMETRYZACJI PROCESÓW GLEBOWYCH \\ NA PROGNOZY METEOROLOGICZNE PROFILI PIONOWYCH
}

\begin{abstract}
Soil and atmosphere boundary layer (ABL) interact with each other and influence physical processes in soil and atmosphere. Quality of numerical weather forecast depends on good mapping of complex soil process (microphysics processes in soil, fluid dynamics in porous media, soil dynamics, water cycle in soil and soil-plant-water relation, thermal processes in the soil etc.) in parameterization soil schemes. Current parameterizations of soil physical processes in TERRA_ML (multilayer soil module of the COSMO meteorological model) were prepared 30 years ago for numerical model with poor resolution. Nowadays operationally numerical models work with much better resolution. So, previous parameterization must have been improved or prepared from the beginning if it is expected improvement quality of numerical weather forecast. The influence of changing parameterization of water flux through the soil for "bare soil" case on vertical meteorological profiles is presented in this paper. This influence can be seen not only in weather forecasts, but also in any areas where the results of meteorological model(s) are used, like decision support systems in emergency situations or modeling of dispersion of air pollutants.
\end{abstract}

Keywords: parameterization of soil processes, vertical meteorological profiles, numerical modeling, multilayer soil model

\section{Multi-Layer Soil module in COSMO model}

Since most of the complex physical processes in the soil occur in a scale smaller than the resolution of domain in numerical weather models, they have to be parameterized to properly take them into account in view of their impact on phenomena in the atmospheric boundary layer. Correct parameterization of hydrological and thermal processes in soil has a significant impact on forecast of vertical profiles of meteorological quantities [1-5] and on the entire meteorology of the boundary layer [6-8]. Consequently, it is very important to understand influence of every complex process in soil [9-14] on processes in the lower part of boundary layer meteorology [1, 3, 4, 6-8]. In the first part of the research a flux of water through the surface soil for the "bare" soil case was analyzed. Dickinson's parameterization

\footnotetext{
${ }^{1}$ Institute of Meteorology and Water Management - National Research Institute, ul. Podleśna 61, 01-673 Warszawa, Poland, phone +48 2256941 34, fax +48 2256943 56, email: grzegorz.duniec@imgw.pl

* Corresponding author: andrzej.mazur@imgw.pl
} 
[15] was introduced 30 years ago and now, due to significant increase of model's domains and resolutions do not give satisfactory results (in terms of accurate weather forecasts). Original Dickinson's parameterization was replaced by Darcy's equation [9-14, 16-19], taking into account a dependency on temperature of water flux in the soil, and, subsequently, with modified Darcy's equation [20] with different features included. Implementation of new solutions in the COSMO model caused noteworthy improvement of forecast's results [20].

In previous work [20] an impact of revised parameterization on forecasts of surface fields of meteorological elements was presented. In this paper an impact of revised parameterization on forecasts of vertical profiles (soundings) is presented.

The TERRA_ML parameterization in the COSMO model (non-hydrostatic, limitedarea atmospheric model for numerical weather forecasts) accounts for the five regular soil types: sand, sandy loam, loam, loamy clay and clay, together with three special soil types: peat, ice and rock [5]. Spatial distribution of basic soil types in Poland, as applied in COSMO model, was shown in previous work [20]. One should keep in mind that neither for ice nor for rock, hydrological processes in the ground are considered. Although potential evaporation is assumed to occur over the ice surface, yet for this kind of ground a value of soil water content, related with vertical water flow, remains unchanged.

In the soil model bare soil evaporation and plant transpiration are computed, and equations of heat conduction and diffusion are solved. Snow melting is also taken into account in computation. In TERRA_ML six layers are assumed for water cycle and seven for thermal processes (see [5, 20]). Total layer of thermal active soil has thickness of $7.29 \mathrm{~m}$, while hydrological active soil $-2.43 \mathrm{~m}$. In this parameterization only hydrological (evapotranspiration, interception reservoir, infiltration of rain etc.) and thermal (temperature of snow-free and snow-covered soil, snow albedo, melting and thawing etc.) processes are considered and capillary transport is neglected.

A detailed mathematical description of parameterization of hydrological and thermal processes in TERRA_ML can be found in COSMO model manual [5]. Theoretical assumptions of this parameterization can be found in a previous paper [20]. However, short introduction is presented below. Description of water flux through the surface layer of soil Eq. (1) was replaced with various options, assembled in Eqs. (2)-(8):

Original parameterization:

$$
\begin{aligned}
F_{m}=\rho_{w} & \left(1+1550 \cdot \frac{D_{\min }}{D_{\max }} \cdot \frac{B-3.7+\frac{5}{B}}{B+5}\right) . \\
& 1.02 \cdot D_{\max } s_{u}^{B+2}\left(\frac{s_{t}}{s_{u}}\right)^{\left\{5.5-0.8 B\left[1+0.1(B-4) \log \frac{K_{0}}{K_{r}}\right]\right\}} \frac{s_{t}}{\sqrt{z_{u} z_{t}}}
\end{aligned}
$$


Option 1:

$$
\begin{aligned}
F_{m}=\rho_{w} & \left(1+1550 \cdot \frac{D_{\min }}{D_{\max }} \cdot \frac{B-3.7+\frac{5}{B}}{B+5}\right) . \\
& 1.02 \cdot D_{\max } s_{u}^{B+2}\left(\frac{s_{t}}{s_{u}}\right)^{\left\{5.5-0.8 B\left[1+0.1(B-4) \log \frac{K_{0}}{K_{r}}\right]\right\}} \frac{s_{t}}{\sqrt{z_{u} z_{t}}}\left(\frac{T}{T_{0}}\right)^{a}
\end{aligned}
$$

Option 2:

$$
F=-D(\theta) \nabla \theta
$$

Option 3:

$$
F=-D(\theta) \exp \left(\frac{T}{T_{0}}\right) \nabla \theta
$$

Option 4:

$$
F=-\alpha(t) D(\theta)\left(\frac{T}{T_{0}}\right)^{a} \nabla \theta
$$

Option 5:

$$
F=-\alpha(t) D(\theta) \exp \left(\frac{T}{T_{0}}\right) \nabla \theta
$$

Option 6:

$$
F=-D(\theta)\left(\frac{T}{T_{0}}\right)^{a} \nabla \theta
$$

Option 7:

$$
F=-\alpha(t) D(\theta)\left(\frac{T}{T_{0}}\right)^{a} \nabla \theta
$$

where: $D_{\min }=2.5 \cdot 10^{-10} \mathrm{~m}^{2} \mathrm{~s}^{-1}$ - minimum soil diffusivity, $D_{\max }=B \Phi_{0} K_{0}\left(\rho_{w m}\right)^{-1}-$ maximum diffusivity, $K_{r}=10^{-5} \mathrm{~ms}^{-1}, K_{0}$ - maximum hydraulic conductivity, $\Phi_{0}=0.2 \mathrm{~m}$ (soil suction), $\rho_{w m}=0.8$, fraction of saturated soil filled by water, nominally 0.5 [15], $B$ - non-dimensional parameter depending on type of soil, $s_{w}, s_{t}$-average of soil water content normalized by the volume of voids for uppermost layer $(0.1 \mathrm{~m}$ thickness $)$ and for a total active layer $(1 \mathrm{~m}$ thickness) respectively, $z_{u}, z_{t}$ - upper most layer and total active layer, respectively, $D(\theta)$ being hydraulic diffusivity, parameter dependent on soil water content, $T$ - being actual soil temperature, $T_{0}=273.15 \mathrm{~K}$, correcting factor (in a parabolic form) to Darcy equation $t_{w}, t_{z}$ - the time of sunrise and sunset, respectively [20], defined in equation:

$$
\alpha(t)=-\frac{0.7}{t_{z}^{2}-t_{w}^{2}} t^{2}+\frac{1.5 t_{z}^{2}-0.8 t_{w}^{2}}{t_{z}^{2}-t_{w}^{2}}
$$


Parameter $a$ in Eqs. (2), (5) and (6) was equal to -1.0, 0, 0.5, 1.0 and 2.0 for all types of soil. In addition, different values of $a$ for different kind of soil (option 7, Eq. (8)) was considered as follows:

- $\quad a=4.74$ for sandy loam;

- $\quad a=2.79$ for sand;

- $a=5.25$ for loam;

- $a=8.17$ for clay loam;

- $a=11.0$ for clay.

Due to the lack of ability to experimental determination of values of parameter $a$ above it was adopted from experiments defining a relationship between soil potential and volumetric water content $[2,21]$. The main goal was to check whether the simultaneous adoption of different values of parameters $a$ for relevant types of soil will affect the quality of the forecast.

\section{Numerical experiments}

For numerical experiments warm (from April $1^{\text {st }}$ to September $30^{\text {th }}$ ) and cold (from January $1^{\text {st }}$ to March $31^{\text {st }}$ and from October $1^{\text {st }}$ to December $31^{\text {st }}$ ) seasons of year 2013 were chosen. Results from observations (data from aerological stations gathered from [22]) were compared with results from COSMO model (reference and with parameterizations changed). Eight aerological stations in Europe and Poland were taken into account: Linderberg, Praha-Libus, Prostejov, Poprad-Ganovce, Leba, Legionowo, Wroclaw, Kaliningrad.

Vertical profiles of the following meteorological elements were considered:

a) air temperature;

b) dew point temperature;

c) relative humidity;

d) wind speed and

e) changes in wind direction with height,

at 30 synoptic levels, from 50 to $15000 \mathrm{~m}$ above mean seal level (amsl.). In particular, this assessment was focused on planetary boundary layer (PBL). As representative ones, results for Praha-Libus will be presented.

\section{Results and discussion}

First, results for cold season at Praha-Libus (Figs. 1-5) were considered.

The numerical average half-year of vertical profiles of air temperature forecast (Fig. 1) and vertical profile for relative humidity (Fig. 3) were improved in the lower part of PBL (up to $800 \mathrm{~m}$ above ground level-agl.), for all options of parameterization of water flux in comparison with measurement. Above that height results for all options converge with measurements. The results for dew point temperature are not satisfactory. Average half-year forecasts of vertical profile of dew point temperature are better for reference Dickinson's parameterization, comparing to the results of other parameterization schemes and to measurement (Fig. 2). 


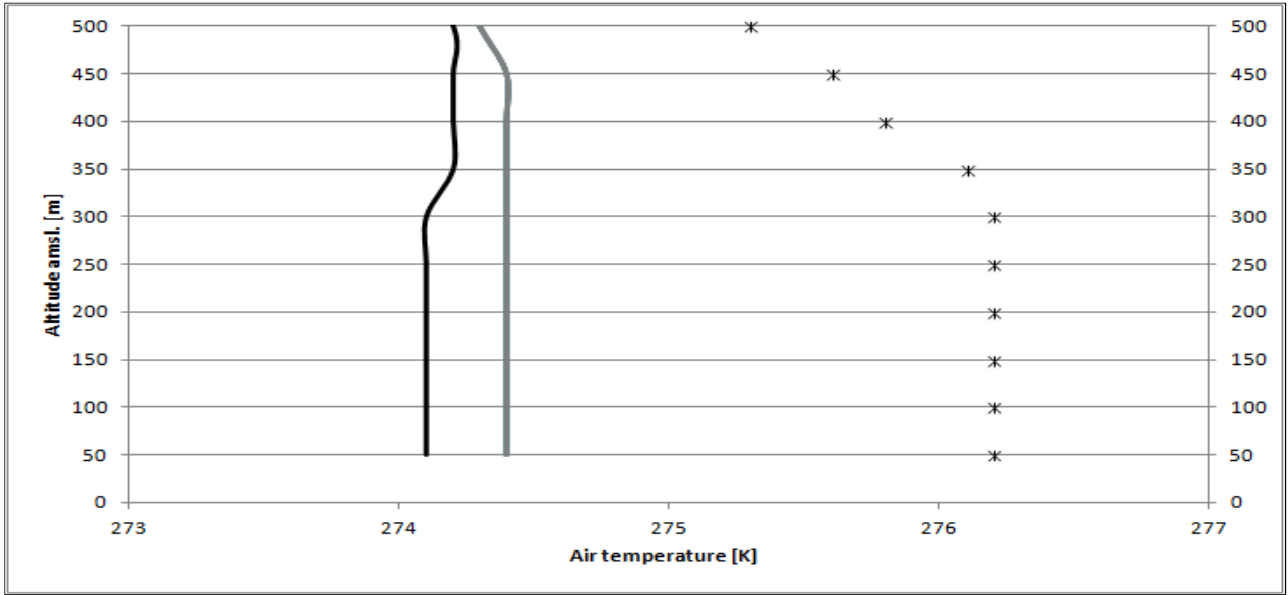

Fig. 1. The vertical profile of air temperature for cold season and for Praha-Libus aerological station. Asterisks mark - measurements; black line - results of reference model version; gray line - results of COSMO model with modified parameterization (option 3, option 4, option 5 with $a=0.5$, option 7 , in grayscale from lightest to darkest, respectively)

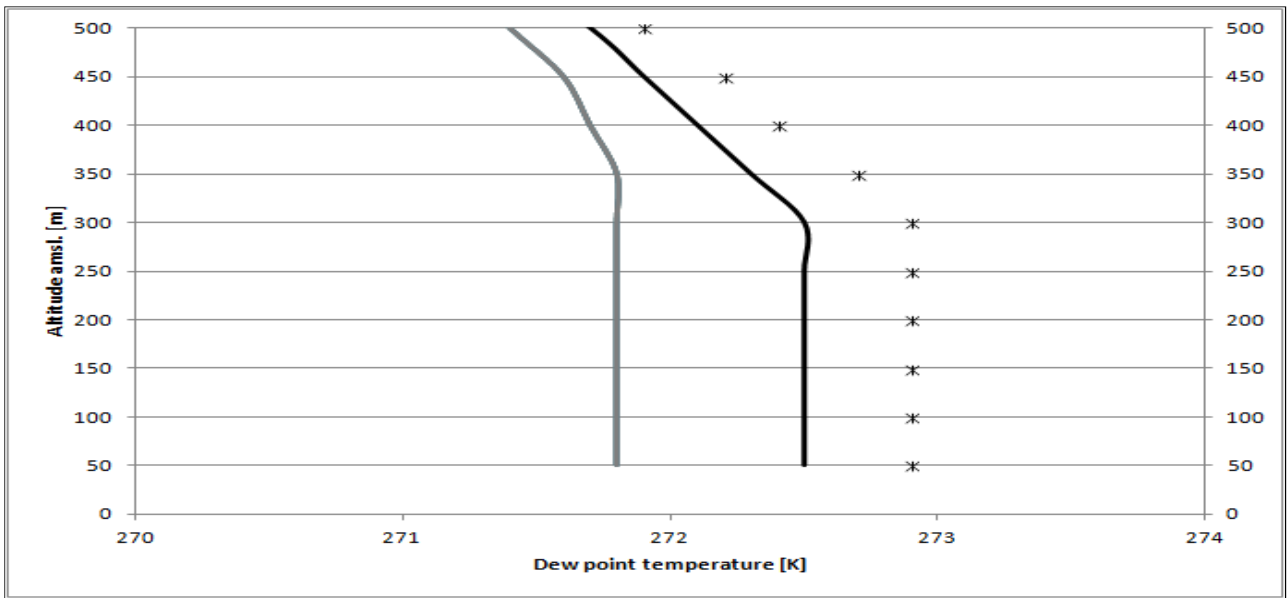

Fig. 2. The vertical profile of dew point temperature for cold season and for Praha-Libus aerological station. Asterisks mark - measurements; black line - results of reference model version; gray line results of COSMO model with modified parameterization (option 3, option 4, option 5 with $a=0.5$, option 7 , in grayscale from lightest to darkest, respectively)

Numerical forecast for vertical profile of wind direction improved only in the middle part of atmospheric boundary layer (ABL), ie from about $300 \mathrm{~m}$ agl., to 500-550 m agl., with parameterization modified according to option 7 (Eq. (8)). In the lower part ABL a worsening of forecast (in comparison with results and with old Dickinson's parameterization) observed. From 550 to $650 \mathrm{~m}$ agl., an improvement of forecast with parameterization options 3 and 4 (Eq. (5) and (6)), respectively is observed, while parameterization options 3 and 5 (Eq. (4) and (7)), respectively gives a good forecast for 
altitude from about 680 to $750 \mathrm{~m}$ agl. For altitude 1750-3000 m agl., an improvement of forecast can be seen for parameterization option 7 (Eq. (8); Fig. 4).

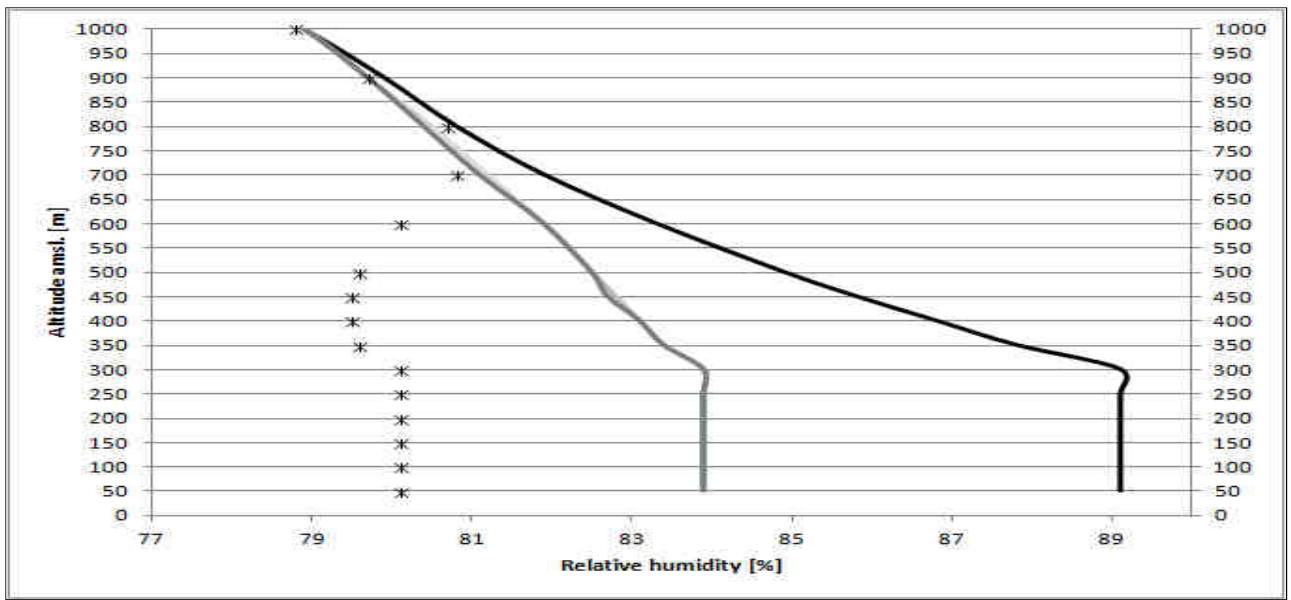

Fig. 3. The vertical profile of relative humidity for cold season and for Praha-Libus aerological station. Asterisks mark - measurements; black line - results of reference model version; gray lines results of COSMO model with modified parameterization (option 3, option 4, option 5 with $a=0.5$, option 7 , in grayscale from lightest to darkest, respectively)

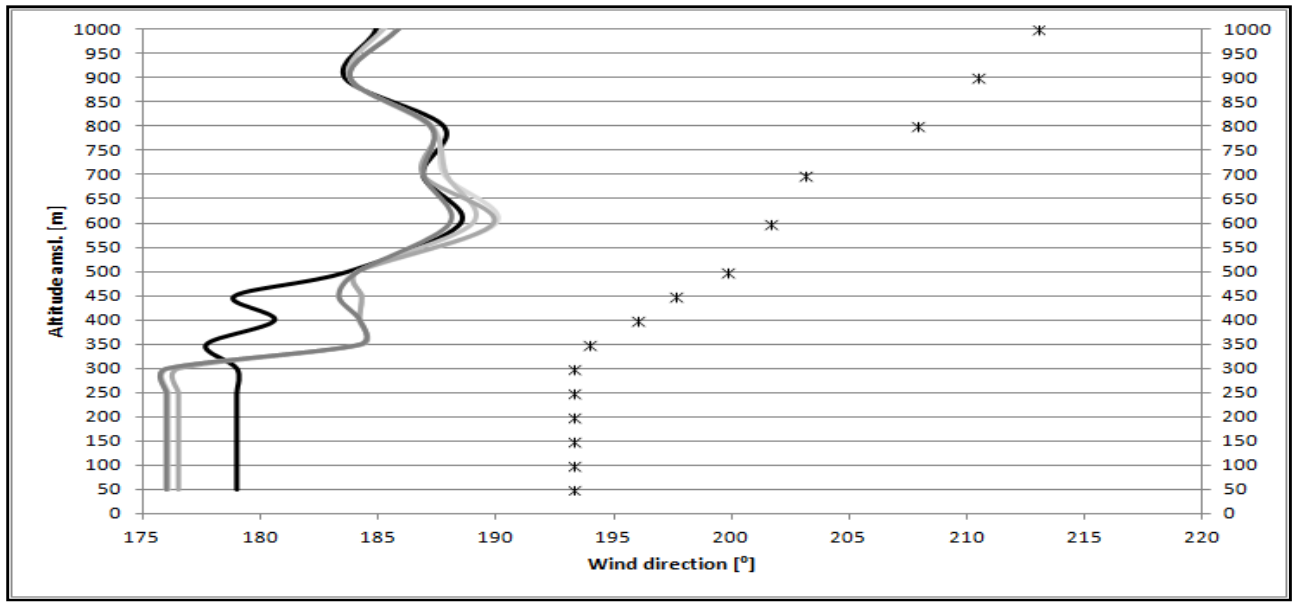

Fig. 4. The vertical profile of wind direction for cold season and for Praha-Libus aerological station. Asterisks mark - measurements; black line - results of reference model version; gray lines results of COSMO model with modified parameterization (option 3, option 4, option 5 with $a=0.5$, option 7 , in grayscale from lightest to darkest, respectively)

A quality of forecasts of wind speed was in general unchanged after implementation of new parameterizations. Small (rather insignificant) improvement can be seen at levels 500 to $900 \mathrm{~m}$ agl. (Fig. 5). 


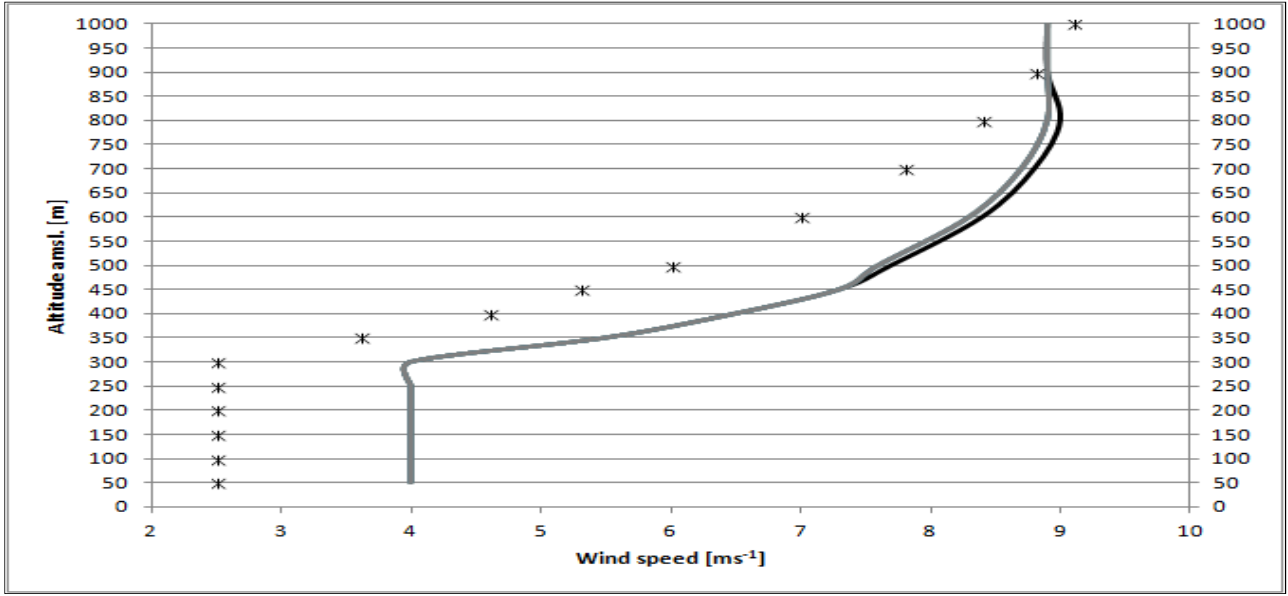

Fig. 5. The vertical profile of wind speed for cold season and for Praha-Libus aerological station. Asterisks mark - measurements; black line - results of reference model version; gray line - results of COSMO model with modified parameterization (option 3, option 4, option 5 with $a=0.5$, option 7 , in grayscale from lightest to darkest, respectively)

Consequently, in Figures 6-10 results for warm season at Praha-Libus are presented.

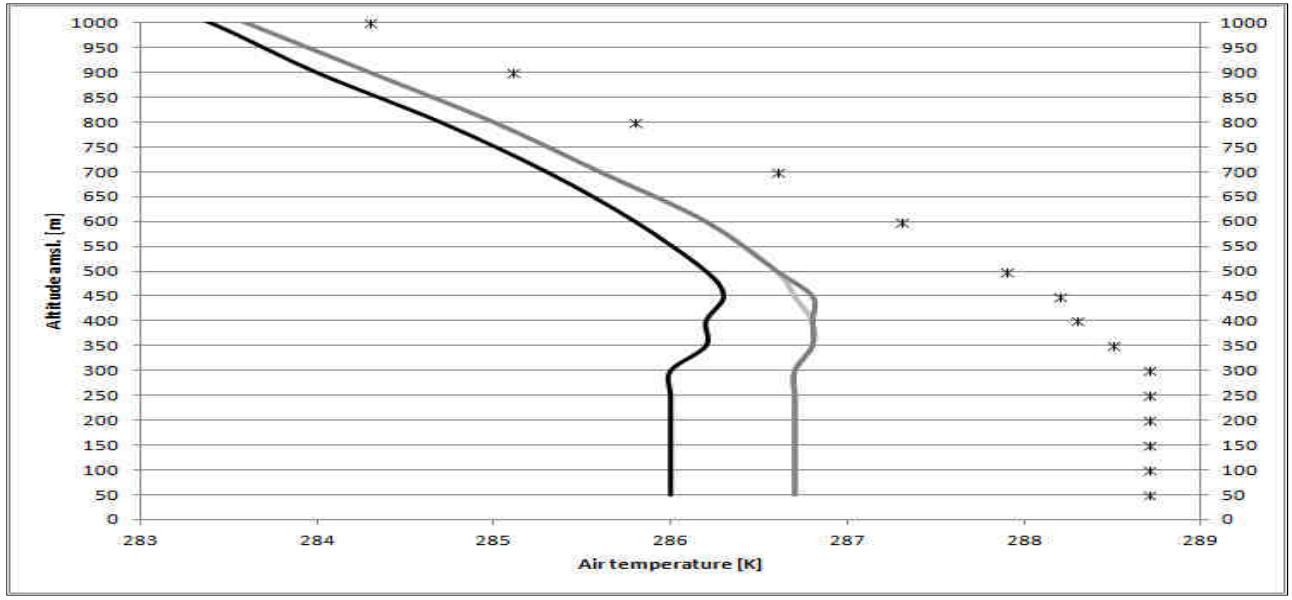

Fig. 6. The vertical profile of air temperature for warm season and for Praha-Libus aerological station. Asterisks mark - measurements; black line - results of reference model version; gray lines results of COSMO model with modified parameterization (option 3, option 4, option 5 with $a=0.5$, option 7 , in grayscale from lightest to darkest, respectively)

Forecasts of vertical profile of air temperature were improved in comparison with result received from reference version of COSMO model and with measurements (Fig. 6). It is interesting that all modified parameterizations gave better forecast of vertical profiles in comparison with measurement and that all "new" results converge. 


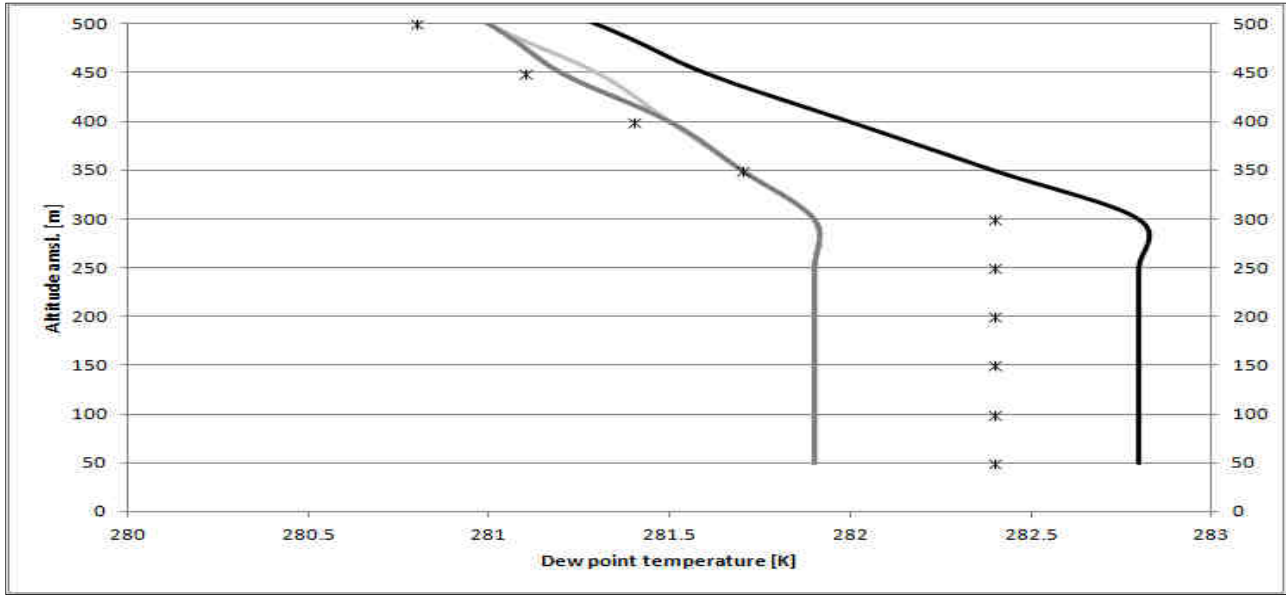

Fig. 7. The vertical profile of dew point temperature for warm season and for Praha-Libus aerological station. Asterisks mark - measurements; black line - results of reference model version; gray lines - results of COSMO model with modified parameterization (option 3, option 4, option 5 with $a=0.5$, option 7 , in grayscale from lightest to darkest, respectively)

It is difficult to state whether the profile of forecast of dew point temperature in the lower part of PBL was improved or not. Numerical forecast based on old Dickinson's parameterization gave values of dew point temperature which overestimated the measurements, while changed parameterization(s) produced forecasts, in general underestimating the measurement results. In fact measured profile of dew point temperature is located almost ideally in-between two forecast profiles. Above $400 \mathrm{~m}$ agl., new results are in good agreement with measurements (Fig. 7).

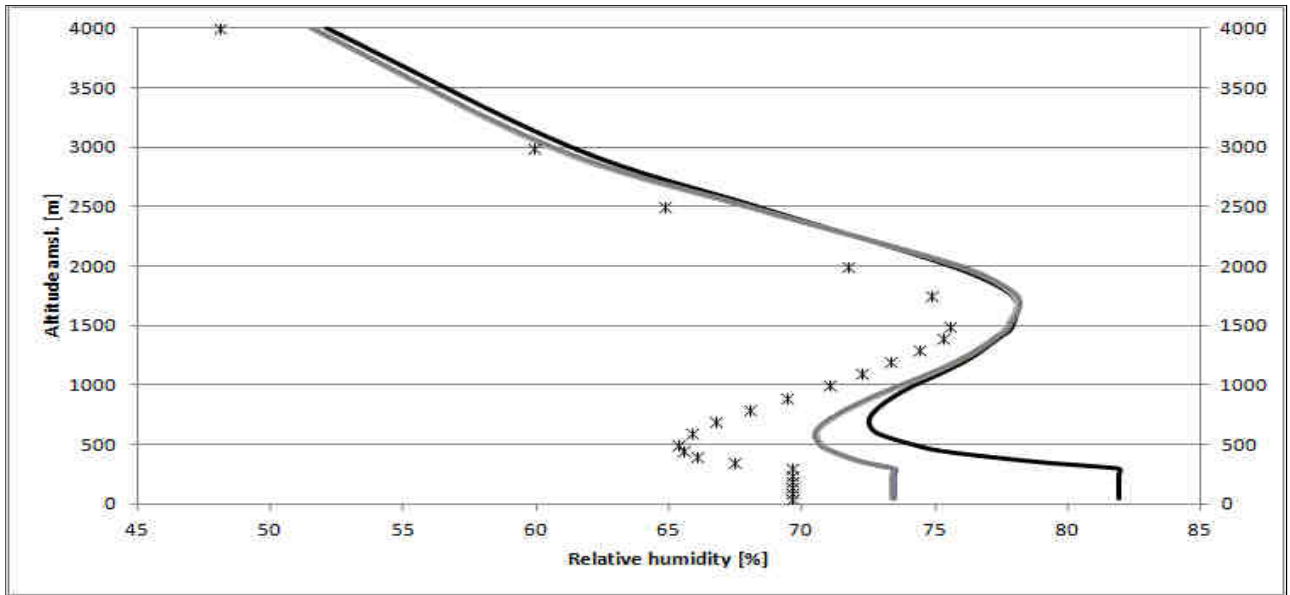

Fig. 8. The vertical profile of relative humidity for warm season and for Praha-Libus aerological station. Asterisks mark - measurements; black line - results of reference model version; gray line - results of COSMO model with modified parameterization (option 3, option 4, option 5 with $a=0.5$, option 7 , in grayscale from lightest to darkest, respectively) 
In the lower part of PBL, up to $1 \mathrm{~km}$ agl., an improvement forecast of vertical profile of relative humidity for warm season is observed. In the upper part of PBL, above $1 \mathrm{~km}$ agl., results for different options of parameterization gave almost identical results, slightly closer to measurements than reference ones (Fig. 8).

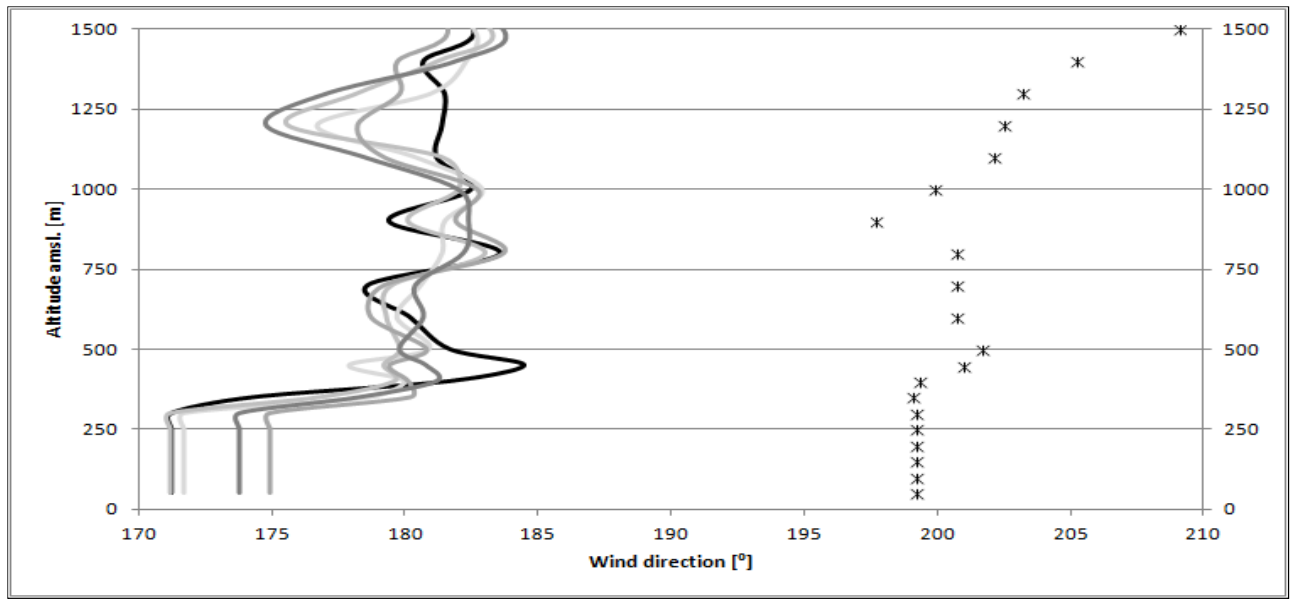

Fig. 9. The vertical profile of wind direction for warm season and for Praha-Libus aerological station. Asterisks mark - measurements; black line - results of reference model version; gray lines results of COSMO model with modified parameterization (option 3, option 4, option 5 with $a=0.5$, option 7 , in grayscale from lightest to darkest, respectively)

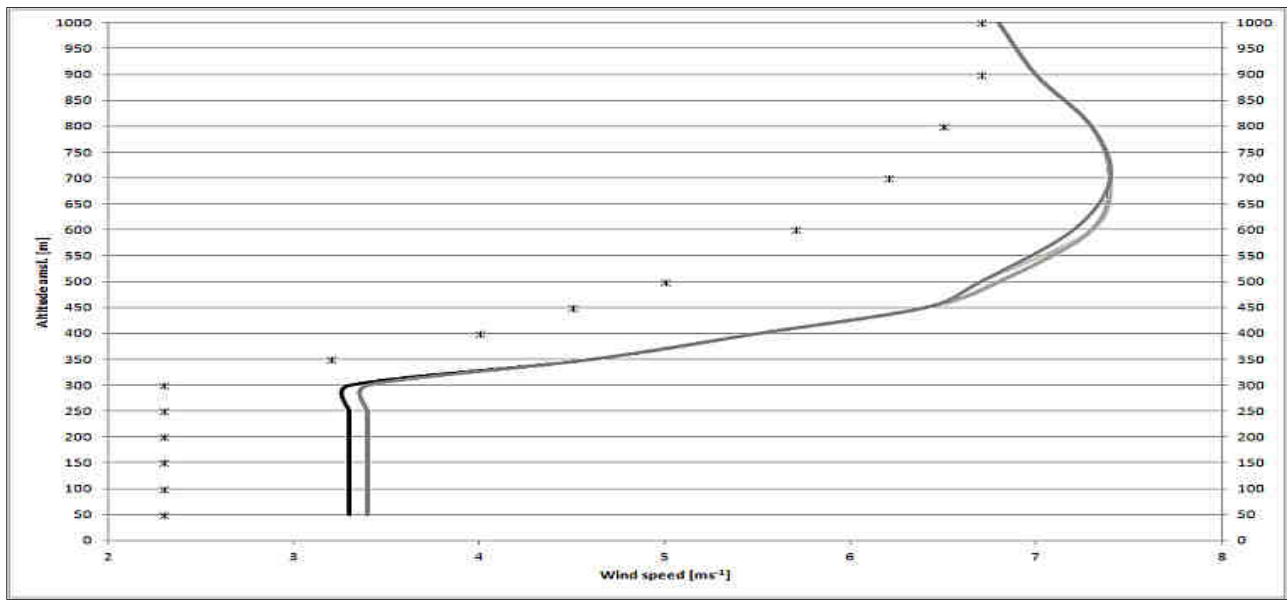

Fig. 10. The vertical profile of wind speed for warm season and for Praha-Libus aerological station. Asterisks mark - measurements; black line - results of reference model version; gray line - results of COSMO model with modified parameterization (option 3, option 4, option 5 with $a=0.5$, option 7 , in grayscale from lightest to darkest, respectively)

Analyzing a vertical forecast profile of wind direction one cannot definitely state whether improvement or worsening can be seen for all altitudes. There are areas where 
results improved, and, on the contrary, areas where the forecast is worse than a reference one (Fig. 9).

Up to $300 \mathrm{~m}$ agl., (in the lower part of PBL) a slight deterioration of forecast of vertical profile of wind speed is observed (Fig. 10). Above this height (in the middle and the upper part of PBL) the same forecast from reference version of COSMO model and for all parameterization options was obtained.

\section{Conclusions}

Currently operational numerical weather prediction models work on high resolution domains. Present parameterization of soil physics implemented in numerical model was developed when the resolution was rather poor so it is a bit outdated, and, hence, cannot give adequate results (valid weather forecast). In order to improve the present description of physical processes in the soil different options of parameterization of water flux through the soil layers (changing current Dickinson's parameterization) were prepared and tested. The "old" parameterization was replaced by Darcy equation, which in the next step was modified by introduction temperature dependence - a correcting factor that depends on time and takes into consideration also a kind of soil.

Based on comparison between monthly average numerical forecasts of vertical profiles of air temperature, dew point temperature, wind speed and wind direction, relative humidity with monthly average aerological observations for eight aerological stations it can be concluded that the following relations were observed as a result of modification of parameterization of water flux:

a) profile of air temperature - results improved;

b) profile of dew point temperature - results not improved;

c) profile of wind direction - results improved above $300 \mathrm{~m}$;

d) profile of wind speed - results slightly changed;

e) profile of relativity humidity - results improved.

It can also be concluded that the consideration of soil temperature in the description of water transport in the soils diversified. Modification of the Dickinson's parameterization affected indirectly other physical processes occurring in the soil, such as runoff of water from soil layers, vertical soil water transport (Richards' equation). Therefore, replacing Dickinson's parameterization in COSMO model by Darcy's equation (coupled also with different modifications) one could expect some impact on results. The impact could be positive or negative. It was expected that if "old" Dickinson's parameterization, which was prepared almost 30 years ago, for models with low spatial resolution, is replaced by a different option(s) of Darcy equation, results should improve. Numerical experiments discussed above confirmed the expectation of improvement. Since the preliminary results are promising, authors intend to continue to modify schemes of parameterizations, taking into account more complex physical processes occurring in the soil as well as vegetation, which have a huge impact on the transport of water and on the variability of water content in the soil.

Another point worth to be raised is that all of considered options, ie modified parameterizations, produced similar results (see Figs. 1-3, 5-8 and 10). It was due to the fact that, in general, the differences between options 1-6 and 7 (as described in equations (2)-(8)), from the mathematical point of view, were relatively small. The situation was different (Figs. 4 and 9) only when wind direction profiles are concerned. It was caused 
during the averaging of results. An averaging procedure for wind direction over the range of 0-360 degrees could produce significant difference of mean results of considered options even for small (in reality) differences between, eg 359 and 0 degrees. However, in most cases all these results were closer to reality (were improved) in comparison to reference parameterization and, moreover, the range of considered processes justified the use of changed parameterization instead.

\section{References}

[1] Kędziora A. Podstawy agrometeorologii (Introduction to Agrometeorology). Poznań: PWRiL; 2008.

[2] Stensrud DJ. Parameterization Schemes - Keys to Understanding Numerical Weather Prediction Models. Cambridge: Cambridge University Press; 2007. DOI: 10.1017/CBO9780511812590.

[3] Moene AF, van Dam JC. Transport in the Atmosphere-Vegetation-Soil Continuum. Cambridge: Cambridge University Press; 2014. DOI: 10.1017/CBO9781139043137.

[4] Vila-Guerau de Arellano J, Van Heerwaarden CC, Van Stratum BJH, Van den Dries K. Atmospheric Boundary Layer. New York: Cambridge University Press; 2015. DOI: 10.1017/CBO9781316117422.

[5] Doms G, Foerstner J, Heise E, Herzog HJ, Mironow D, Raschendorfer M, Reinhart T. A Description of the Nonhydrostatic Regional COSMO Model. Part II: Physical Parameterization', Tech. Rep., DWD, 2011. http://www.cosmo-model.org/content/model/documentation/core/cosmoPhysParamtr.pdf (access: 11.12.2015).

[6] Stull RB. An Introduction to Boundary Layer Meteorology. Springer, USA; 1988. DOI: 10.1007/978-94-009-3027-8.

[7] Garrat JR. The Atmospheric Boundary Layer. Cambridge: Cambridge University Press, USA; 1992. DOI: 10.1002/qj.49712051919.

[8] Pielke RA. Mesoscale Meteorological Modeling. San Diego: Academic Press; 2002. Vol. 78. DOI: 10.1256/00359000260384389.

[9] Hillel D. Environmental Soil Physics. London: Academic Press; 1998.

[10] Hillel D. Introduction to Environmental Soil Physics. Amsterdam: Elsevier Science, The Netherlands; 2004.DOI: 10.1111/j.1365-2389.2005.0756d.x.

[11] Hillel D. Soil in the Environment. Crucible of Terrestrial Life. London: Academic Press; 2008. DOI: 10.1002/ieam.5630040427.

[12] Bear J. Dynamics of Fluids in Porous Media. New York, USA: Dover Publications; 1972. DOI: $10.1017 /$ S0022112073210662.

[13] Bear J, Cheng AH-D. Modeling Groundwater Flow and Contaminant Transport. Dordrecht, The Netherlands: Springer; 2010. DOI: 10.1007/978-1-4020-6682-5.

[14] Novak V. Evapotranspiration in the Soil-Plant-Atmosphere System. Dordrecht, The Netherlands: Springer; 2012. DOI: 10.1007/978-94-007-3840-9.

[15] Dickinson RE. Modeling evapotranspiration for three-dimensional global climate models. In: Climate Processes and Climate Sensitivity. Hansen JE, Takahashi T, editors. Washington D.C.: Geophysical Monograph 29, 1984, Volume 5, pp. 58-72. DOI: 10.1029/GM029p0058.

[16] Warrick AW. Soil Water Dynamics. Oxford, UK: Oxford University Press Inc; 2003. DOI: 10.1023/B:ENVR.0000046450.62059.62.

[17] Rose C. An Introduction to the Environmental Physics of Soil, Water and Watersheds. Cambridge: Cambridge University Press; 2004. DOI: 10.1111/j.1365-2389.2004.0694c.x.

[18] Hanks RJ. Applied Soil Physics-Soil Water and Temperature Application, 2nd Edition, New York. USA: Springer-Verlag; 1992. DOI: 10.1007/978-1-4612-2938-4.

[19] Bittelli M, Campbell GS, Tomei F. Soil Physics with Python: Transport in the Soil-Plant-Atmosphere System. Oxford, UK: Oxford University Press; 2015. DOI: 10.1093/acprof:oso/9780199683093.001.0001.

[20] Duniec G, Mazur A. Modified Description of Soil Processes vs. Quality of Numerical Weather Forecasts "Bare" Soil Case. Ecol Chem Eng S. 2015;22(4):659-673. DOI: 10.1515/eces-2015-0040.

[21] Radcliffe DE, Simunek J. Soil Physics with HYDRUS - Modeling with Applications. Boca Raton. Florida, USA: CRC Press; 2010.

[22] http://weather.uwyo.edu/upperair/sounding.html. 